\title{
Na curva das águas: a África de Serpa Pinto entre a Antropologia e a História
}

\author{
Heloisa Pires Lima ${ }^{1}$
}

Às vésperas da Conferência de Berlim (1884-1885), que precipitou a partilha do continente negro, a representação de África no acervo de relatos de viagem produzidos sobre a região oferece um conjunto ímpar para análises. Restringindo o foco à historiografia e etnografia produzidas a partir de Portugal, um dos exemplares disponíveis para olhares atentos é a obra Como eu atravessei a África do Atlântico ao mar Índico, viagem de Benguella a contra-costa a-traves de regiões desconhecidas; determinações geographicas e estudos etnographicos. Assinada por Alexandre Alberto da Rocha de Serpa Pinto (18461900), a publicação (1881) está relacionada ao empreendimento organizado pela Comissão de Cartografia de uma Expedição Portuguesa à África Central e Meridional, em 1877.

O material permanece disponível para exames segundo a natureza do estudo que o reivindicar. A tradicional interlocução teórico-metodológica no âmbito das ciências sociais permite prever a interdisciplinaridade nessa verificação. No entanto, o mote será bastante apropriado para algumas indagações a serem desenvolvidas neste artigo acerca do relacionamento entre as disciplinas Antropologia e História, tendo para intersecção o livro de viagem como modalidade literária.

Iniciemos supondo a dúvida ingênua sobre o que faz, então, a leitura de um documento do passado ser definida como antropológica e não histórica. Ora, se na pósmodernidade fugimos de qualquer concepção essencialista para tratar o tema das identidades, o mesmo princípio abarca as doutrinas que perfilam as áreas de conhecimento. Por sua vez, a perspectiva interdisciplinar camufla, cada vez mais, os limites entre um e outro campo do saber. É certo que colaborem entre si, constituam regiões de fronteira, estabeleçam fluxo de trocas onde transitam vocábulos afins. E enfrentar a problemática

\footnotetext{
${ }^{1}$ Doutora em Antropologia Social titulada pela Universidade de São Paulo. Pesquisadora da Cátedra Jaime Cortesão (2005).
} 
teórica de fundo em prol do específico na transdiciplinaridade abastece diferentes linhagens intelectuais, nenhuma delas definitiva.

Para o tema privilegiado, poucos analistas já se valem da facilidade em considerar a preeminência factual dos acontecimentos como uma perspectiva historiográfica absoluta. Os estudos preocupados com uma história social dos costumes, das mentalidades, uma abordagem cultural, mais estrutural que factual constituem uma tradição desde o século XVIII. Estes poderiam aludir ao historiador Legrand d'Aussy. Em História da vida privada dos franceses (1782), é conhecida sua insatisfação com o tipo de história que se vinha fazendo até então, uma história essencialmente política e voltada para os grandes acontecimentos e para os feitos dos reis, generais etc. Mais contemporaneamente, perceber nas expressões culturais de uma sociedade um objeto histórico é a proposta da chamada escola dos Annales, dividida em três gerações a partir de 1929: a primeira representada por Lucien Febvre e Marc Bloch - seus fundadores - a segunda marcada pela liderança de Fernand Braudel e, por fim, a terceira_geração integra por, entre outros, Georges Duby, Jacques Le Goff e Emmanuel Le Roy Ladurie. Classificação esta, também provisória e ciente de não haver consenso. $^{2}$

Por outro lado, a temática do documento histórico para o antropólogo pode reivindicar a participação de Marshall Sahlins quando ele centraliza o problema nas suas incursões teóricas. Sobretudo por ser esta a questão que ele dirige aos antropólogos sob uma ótica que exacerba os vínculos entre ordem cultural e mudanças históricas. ${ }^{3}$ Ao demonstrar como os efeitos das forças materiais globais dependem dos diversos modos como estas são mediadas por esquemas culturais locais, ele propõe o que define ser uma antropologia da história, nesse momento às voltas com um repertório havaiano. O argumento central defende que a "estrutura" pode ser um objeto histórico, o que leva a cancelar, justamente, a oposição entre "estrutura" e "história". 4

\footnotetext{
${ }^{2}$ Ver, entre outros, Burke, P. 1990

3 Trabalhos do autor como "Other Times, Other Customs: The Anthropology of History” (1982) e "Structure and History" (1983), contribuíram para a questão por ele perseguida que culminam na obra mais conhecida do autor. Em Ilhas de História, publicada originalmente nos Estados Unidos, em 1985, a relação entre Antropologia e História é central.

${ }^{4}$ Sahlins, M.1994, p. 8
} 
A ordem cultural seria constituída na sociedade, mas vivenciada pelos indivíduos, o que Marshall Sahlins define como estrutura na convenção e na ação ${ }^{5}$. Essa ênfase em observar como os significados são colocados em risco na ação, passando assim por reavaliações funcionais, ${ }^{6}$ auxiliaria a compreensão das assinaturas culturais distintas frente aos acontecimentos históricos. É a contingência dos eventos e a recorrência de estruturas o problema central desenvolvido nesse pensamento. ${ }^{7}$ Por conclusão, qualquer uma das duas seria insuficiente se considerada individualmente. Exatamente por isso o autor cria uma terceira categoria como síntese situacional: a "estrutura da conjuntura." O constructo é estratégico para Marshall Sahlins determinar o que chama de riscos simbólicos e, ao mesmo tempo, reificações seletivas. Segue-se daí que ordens culturais diversas tenham modos próprios de produção histórica. ${ }^{8}$ Portanto, sem perder de vista a estrutura dos enunciados, o autor buscava o dinamismo interno que estes pudessem vir a apresentar. E o mais importante, os pontos de contato entre as perspectivas da História e a da Antropologia ficavam bastante evidenciados.

O exame da interlocução entre as duas disciplinas também pode acompanhar esforços como os realizados por Nilma Gomes e Lilia Schwarcz ${ }^{9}$. Elas reúnem uma série de ensaios pautados em textos produzidos por pensadores clássicos das ciências sociais. O objetivo geral se atém a como estes se colocam diante do diálogo entre antropologia e história. Os artigos primam por delimitar instantes sui generis dos autores examinados. Acompanhar o momento da elaboração para o uso dos constructos particulares criados pelos argumentos que os justificam leva a perceber como os autores destacam uma ou outra disciplina e o quanto priorizam uma delas em suas leituras. O trabalho ressalta as diferentes metodologias da demonstração desejada e o sistema lógico do pensamento que as propõe. A partir de alguns casos, a leitura antropológica prioriza tanto o seu dinamismo quanto deixa à mostra a noção de história com a qual os momentos dos autores estabeleceram vínculos.

\footnotetext{
${ }^{5}$ Sahlins,M. 1994, p. 9

${ }^{6}$ Sahlins,M. 1994, p. 11

7 idem ibidem

8 idem, ibidem

${ }^{9}$ Gomes, Nilma Lino \& Schwarcz, Lilia K. 2000
} 
No fundo, frente ao panorama das antropologias históricas ou das histórias antropológicas ${ }^{10} \mathrm{o}$ desafio é perfilar as medidas cautelares que evitem uma disciplina de se perder na outra. A consciência do relacionamento talvez seja a única garantia.

Todavia, a grande teoria se vale de problemas mais básicos. Os trabalhos antropológicos que se voltam para o passado lidam com o enfrentamento das fontes e necessitam dominar cada vez mais os procedimentos para a tradução de documentos antigos, assuntos que não fizeram parte, tradicionalmente, do currículo de formação. Áreas como a antropologia visual têm propiciado a especialização para a leitura de acervos iconográficos, expandindo uma tradição em objetos inéditos. Por exemplo, a etnologia das cartografias.

Dos aspectos conduzidos até aqui, não há como deixar de ressaltar o narrador, aquele que edita o conhecimento produzido e a densidade ao lidar com a área que pretende evidenciar. Ainda retomando Marshall Sahlins, em seu trabalho investigativo ele perseguiu a história das ilhas dos mares do sul (p.20), freqüentou arquivos, selecionou registros temporal e culturalmente remotos. Parecendo historiador, mas sendo de fato um antropólogo perspicaz, enfrentou o universo da lógica cultural havaiana para a elaboração de sua teoria. No alerta que emite acerca das oposições o faz para sugerir que não se deva partir daquelas entronizadas nas ciências sociais e históricas (pág. 47), do tipo estado e processo ou substância e ação. As problematizações sugeridas por Marshall Sahlins - os esquemas culturais são relativos, as categorias culturais se pensam, as referências correm riscos na práxis, as ordens culturais têm sua historicidade própria, a vida cultural das formas elementares apresenta lógicas ambíguas, os sistemas não se opõem aos eventos ainda são parâmetros importantes para o debate que não cessa. E, da mesma forma, as críticas dirigidas à organização das ideias sahlinianas, como as promovidas pelo professor de Antropologia Gananath Obeyesekere na Universidade de Princeton.

Aliás, nessa mesma universidade as discussões sobre o tema oferecem, dentre os ângulos ordinários, a participação do historiador Robert Darton ao lado de Clifford Geertz, professor sênior de Antropologia na instituição. Ambos ministraram por muitos anos o

\footnotetext{
${ }^{10}$ Para a polêmica em torno das relações entre história e antropologia, Schwarcz retoma e aprofunda alguns desses pontos no artigo "Questões de Fronteira" (2005).
} 
seminário que tratava da interlocução entre História e Antropologia, deixando um arsenal teórico para a posteridade ${ }^{11}$.

O objetivo aqui não é elencar os personagens antropólogos dessa história porque as nuanças seriam muitas. As datadas como as dos estudos promovidos pelo antropólogo Evans-Pritchard em seu artigo de 1961 intitulado "Antropologia e História” é fundamental na cartografia da problemática das sociedades sem escrita. Da mesma forma, como negligenciar o percurso do paradigma levisstrausiano e a polêmica que atribui a seu pensamento deixar a História de lado? Enfim, diferentes linhagens intelectuais desafiam as ordenações teóricas das áreas de conhecimento que insistem em perfilar suas peculiaridades. Mas, como bem disse Malinowski: "Imagine-se, de repente, sentado, rodeado por todos os apetrechos, sozinho em uma praia tropical perto de uma aldeia nativa, enquanto a lancha ou escaler que o trouxe navega até desaparecer de vista" ${ }^{12}$.

\section{$\underline{\text { Uma literatura como aldeia }}$}

De imediato, o caso da obra referida no início do artigo remete ao âmbito mais genérico dos interesses imperialistas na região africana. O campo, neste momento, é uma obra produzida por uma sociedade num tempo remoto. Mas, considerando o alerta de Schwarcz, não se constrói uma disciplina por um recorte - o presente ou o passado. ${ }^{13} \mathrm{O}$ privilégio do olhar antropológico (são várias antropologias) procura recolher a ordem dos significados resguardada na lógica interna que organizou sua redação. Os eventuais desenhos e fotografias ali contidos complementam uma suposta imagem edificada de império. A tarefa orientadora calcula o arranjo das informações devidamente selecionadas na autoria original a constituir uma fórmula que organiza a percepção de uma certa África. O exemplar elabora um argumento cultural ao longo das narrativas. Embora tais imagens resultem de momentos distintos na sua dimensão histórica, concorrem com efeitos diversos no plano estético: há para nelas observar os significados desse atravessar e produzir conhecimento conforme a intenção elucidada no título Como

\footnotetext{
${ }^{11} \mathrm{http} / / / \mathrm{www}$. revistatopoi.org/numeros_anteriores/topoi05/topoi5ent.pdf (Acessado em maio de 2013).

${ }^{12}$ Marcus, G, 2004

${ }^{13}$ Schwarcz, L. 1999
} 
eu atravessei a África do Atlântico ao mar Índico, viagem de Benguella a contra-costa a-traves de regiões desconhecidas. $\mathrm{O}$ subtítulo, determinacoes geographicas e estudos etnographicos, procura afirmar a autoridade da escritura sobre o campo da geografia e da etnografia e já sugere, para circunscrição, certa historicidade envolvendo o uso dessas noções (sentidos percebidos e dimensionados em seu dinamismo ao longo da narrativa).

Os livros que resultam de viagens exploratórias em África e explicitam propósitos científicos formam um corpus documental para estudos acerca das representações encontradas em seu interior. A periodização que abarca os anos 1870 até a $1^{\text {a }}$ Guerra encerra intensas disputas políticas para a legitimação de monopólios territoriais e fluviais africanos entre os países europeus, sobretudo Bélgica, França, Grã Bretanha, Alemanha e Portugal. Na primeira fase, os anos 1870, descobrir os cursos dos rios Quanzo, Cubango e Tohicapa, entre Luanda e Moçambique, alimentava o sonho português do mapa "cor- derosa". Este indicava os limites pretendidos por Portugal numa extensão entre o Atlântico e o Índico, unindo os territórios de Angola à Moçambique, o que incluiria os atuais Zimbábue e grande parte da Zâmbia.

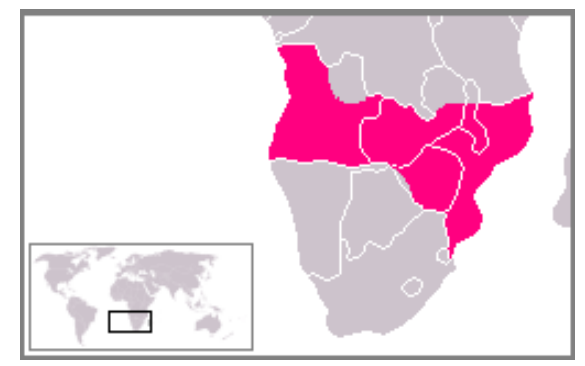

A disputa diplomática pela legitimidade sobre territórios africanos demandou a elaboração de estratégias com vista a manter a hegemonia sobre as possessões. Nessa dinâmica, enquanto o jogo de interesses se desenrolava nos gabinetes das metrópoles européias, a presença portuguesa efetiva nas áreas africanas limitava-se a pouco mais do que plataformas comerciais de pequeno porte ou postos missionários. Portugal, que até então reivindicava o "direito histórico" sobre os domínios territoriais, na medida em que as negociações acirravam disputas entre os países, se viu obrigado a expandir a conquista 
costeira em direção ao interior do continente, o que deu lugar a inúmeras "guerras de pacificação". 14

A despeito dos informes mais gerais, os diários de viagem permanecem reivindicando a condição de testemunhas oculares em tais processos. Seja por desenharem o território, decodificarem os elementos da paisagem, proporem a definição das fronteiras, seja pelas notícias de uma humanidade africana com a qual a expedição se deparava. A noção semiótica de representação ${ }^{15}$ é, necessariamente, o ponto de partida. Portanto, não é sobre como a África e os habitantes são ou viveram na realidade, mas sobre o modo como foram percebidos e representados, no caso, por Serpa Pinto durante o percurso dos compêndios indicados para exame.

Em específico, o registro possibilita identificar concepções acerca de África e dos africanos no âmbito do imaginário português ressignificados por uma conjuntura histórica particular. Nos informes contingenciais, a viagem descrita teria sido organizada pela Comissão de Cartografia de uma Expedição Portuguesa à África Central e Meridional no ano de 1877. Além de Serpa Pinto, então oficial do exército, participaram da empreitada os oficiais de Marinha Hermenegildo Capelo e Roberto Ivens. Esta iniciativa que tem Angola como ponto de partida, acabará por se dividir em duas. Os oficiais de Marinha avançaram para o Norte, a princípio, de acordo com as ordens mais precisas recebidas pela Comissão de Cartografia. Por sua vez, a de Serpa Pinto avança para leste mais de acordo com a política desenvolvida por Luciano Cordeiro e a Sociedade de Geografia de Lisboa. Há,

\footnotetext{
${ }^{14}$ Hernandez, L (2005):510

${ }^{15}$ A semiótica - como prática de descrição e análise da significação - está preocupada com aqueles objetos que resultam de um processo de construção social. Conforme as direções da linguística estruturalista, a representação envolve um significado (conceito, idéia) e um significante (uma inscrição, uma marca material: som, letra, imagem, sinais manuais). O processo de significação é fundamentalmente social, isto é, precisamente aqueles objetos que, na formulação de Saussure, podem ser caracterizados pela relação "significante/significado" - signos. Saussure, tendo como foco a língua, destacou o caráter arbitrário do signo. Não existe nenhuma relação intrínseca, "natural", entre significante e significado: um significante determinado deve sua forma e sua conexão com um determinado significado exclusivamente à convenção social. Na ausência desse vínculo "natural", um determinado signo só se destaca em sua singularidade e identidade por ser diferente de outros signos numa cadeia de significação. Aquilo que um signo é só fica estabelecido nessa cadeia de diferenças. Sua identidade é sempre dependente da diferença. A semiótica póssaussureana amplia o terreno da significação para signos que extrapolam o domínio da língua.
} 
portanto, dois ambientes institucionais em relação: a marinha na peculiaridade dessa comissão de cartografia e a Sociedade de Geografia de Lisboa. ${ }^{16}$

De fato, esta é uma expedição dentre os inúmeros feitos envolvendo a expansão política e econômica europeia no período da segunda metade do século dezenove até a $1^{\mathrm{a}}$ guerra mundial. As anotações que dela derivam buscam responder as demandas pela conquista efetiva, a definição do traçado e a construção de sentidos para as fronteiras imperiais $^{17}$. Por sua vez, recolher elementos que auxiliem perscrutar algumas das intenções ao representar uma África pouco conhecida dimensionam as práticas coletivas de atribuir significados aos mundos africanos evidenciando certa Europa para posteriores relações. Além da própria ideia de nação na qual a proposta se baseia, permite levantar para reflexão a oficialidade do relato.

Para retomar o caso em particular, a vertente relacionada aos editores da obra demonstra sua relevância. Pois o livro de Serpa Pinto foi publicado como resultado da expedição anunciada na capa. No mesmo ano também saiu a edição assinada por Roberto Ivens, participante da expedição inicial e oficial, com o título - De Benguela às Terras de Iaca. Instigante é perceber que a primeira foi preparada em Londres por Sampson Low, Marston, Searle e Rivington. Já a publicação de Roberto Ivens apareceu em Lisboa como edição do autor. Mais um dado inicial curioso refere-se ao fato da Royal Geographycal Society of London agraciar apenas Serpa Pinto pelo trabalho com a Founder's medal, ainda em 1881. A tradução para o francês e para o inglês acontece na mesma época, exibindo o interesse dos editores britânicos nas informações ali contidas e o prestígio que os mesmos atribuem ao explorador português. Portanto, o exame colado no aspecto editorial pode elucidar algumas das interlocuções institucionais. No caso em questão, com as sociedades de geografia de Lisboa, mas também com as de Londres.

16 A Sociedade de Geografia de Lisboa, fundada no ano de 1875, produz a publicação do Boletim da Sociedade de Geografia de Lisboa. Nesse início, a instituição criou a Comissão Nacional de exploração e civilização da África. A instituição expressa o momento de viragem dos interesses pelo continente africano sendo suas ações determinantes. Promovem expedições geográficas (recorrendo a financiamento por subscrição nacional) e contribuindo para a definição de uma política colonial portuguesa em África.

${ }^{17}$ Hernandez (2005:71) informa que o uso do termo imperialismo pode ser remetido à Inglaterra vitoriana quando na década de 1870 dava nome a uma política orientada para criar uma federação imperial baseada no fortalecimento da unidade dos Estados autônomos sob o domínio inglês. No decorrer das discussões sobre a conquista colonial o termo foi incorporado ao vocabulário político e jornalístico europeu. 
Estas são algumas das nuanças para revisitar esse material, que favorecem a percepção dos diferentes tempos envolvidos no empreendimento: a viagem e a obra sobre a viagem. Nesse sentido, o momento de estabelecer princípios para a expedição (1877) é distinto do tempo em que ocorreu a "travessia". Quando Serpa Pinto redigiu os trechos que se tornaram públicos? Teriam estes ocorrido enquanto durou a viagem ou haveria inscrições posteriores? Em que momento realizou os desenhos? O registro poderia ter sido executado de memória? Cada anotação dialoga com todas as demais. A circunstância da seleção do acervo acumulado para ser incluído na edição final dos compêndios é uma nova prerrogativa temporal.

Nesse sentido, a biografia da obra se equaliza em importância à do autor português que, aliás (no detalhe), viveu a infância no Brasil. Não tão particular assim, o foco na produção editorial é um dos ângulos envolvendo a circulação de argumentos públicos que se servem de significados atribuídos à África por europeus às vésperas da Conferência de Berlim (entre dezembro de 1884 e fevereiro de 1885). O processo de partilha do continente e de sua ocupação efetiva segue cronologias diferentes. No que se refere ao império português ocorre desde 1870, em zonas de antigas ocupações e outras não ocupadas. O ano de publicação da obra, 1877, se insere nas políticas de ultramar portuguesas no contexto da Partilha, cujo processo inicia-se nas décadas anteriores. Isto se o estudo ficar apenas com a fase da produção da obra, pois poderia enfrentar a questão da receptividade relacionada ao prestígio que esta, eventualmente, obteve nos diferentes contextos que a própria narrativa indica.

\section{$\underline{\text { O negativo da foto }}$}

O material para análises trata de uma travessia do Atlântico ao mar Índico através de regiões desconhecidas. No entanto, ela está carregada de significados construídos numa relação intercultural. E este é o âmbito a ressaltar, afinando o foco de modo a expor a densidade da figura do explorador do século XIX. Afinal, ele tem como tarefa traçar mapas, itinerários e rotas de viagem em terras desconhecidas para facultar as imagens do interior da África. Submetido a uma série de circunstâncias políticas e de logística expedicionária, ele se encontra sob o olhar dos habitantes africanos ou dos soberanos locais, com os quais 
terá que estabelecer negociações de toda a ordem. A organização que Serpa Pinto deu aos capítulos oferece inúmeras pistas nessa direção. Dois dos iniciais receberam os seguintes títulos: "Capítulo I. Em busca de carregadores" e "Capítulo II. Ainda em busca de carregadores". Por essa nuança, surge uma importante via de acesso ao contexto da produção. Trata-se da paisagem humana que vai surgindo desse universo desconhecido do explorador. A dificuldade para conseguir carregadores é um dado excepcional. Haveria negativa local para a atividade de carregar a parafernália expedicionária?

Comumente os relatos de viagem do período em sua apreensão da África e dos africanos são vistos como expressões do eurocentrismo e da vitória imperialista colonial sobre o continente. Sem negá-los, o detalhe concorre para indagações sobre como os habitantes africanos lidavam com as expedições que desembarcavam em seus territórios. O objeto da análise passa a notar o negativo da foto, ou seja, o destaque a recolher é a perspectiva das contendas enfrentadas pela figura do explorador, dos habitantes que o observam, dos atores locais que chamaram a atenção a ponto de entrarem para a narrativa. Os personagens que surgem no registro revelam o escopo de visão do autor sobre a sociedade construída no relato. Os detalhes dos ambientes que aparecem referidos, os personagens mais ou menos destacados, a posição que ocupam no cenário, tudo faz parte de uma lógica com vistas a orientar o julgamento do leitor. As categorias organizadas segundo um ponto de vista metodológico nessa autoria se servem de linguagens que fixam o instante escolhido para ser exemplar. A seleção do narrador mostra ao que ele se ateve como faces de uma África que se impõe ao registro. Todavia, que também se expõe. A perspectiva a considerar está nos indícios de não haver unilateralidade na confecção das imagens levando a supor os encontros, as negociações e as resistências locais. 
216

A CARABINA D'EL-REI.

Os machados de guerra, frechas e azagaias, vẽm-lhes dos Luchazes, e as enxadas dos Ganguelas, Nhembas e Gonzellos.

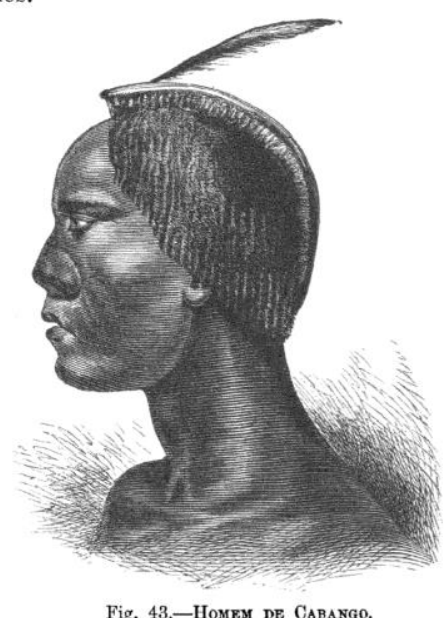

Este soba, que se chama Chaquiunde, é um pouco falto de probidade, o que não admira muito. Veio, depois de larga conversa, fazer-me exigencias, allegando ter-me dado um boi. Vi-me na necessidade de o pôr fora do acampamento; mas elle, vendo a aspreza com que eu o tratava, mostrou-se contente, e explicou a sua impertinencia, desculpando-se com os seus macotas, que o tinham aconselhado a fazer grandes exigencias, e que o que pedia era para elles, pois que a elle eu tinha dado um presente superior ao valor do boi.

Tendo chegado os dois Quimbandes com o meu barco, resolvi seguir no dia immediato.

Como já dito, a obra de Serpa Pinto em questão oferece como linguagens a iconográfica e a escrita, mais o diálogo entre elas para o modo como foram percebidos os africanos em seus territórios. A legenda é um item a ser delimitado por conter o destaque que o autor ressalta na cena.

Cada unidade colocada em relação com o conjunto que se apresenta em dois compêndios informa o espaço geográfico descrito na escritura e na iconografia ao lado dos informes etnoculturais. O relato esconde ou deixa à mostra heterogeneidades? O que há para reparar sobre a articulação da paisagem natural com a social, a arquitetura dos tipos humanos, o que é propagandeado acerca dos costumes? As sociedades descritas oferecem enredos que podem auxiliar na retomada dos sentidos mais amplos dessa presença na elaboração de uma determinada África sem perder de vista os vínculos com a noção de 
império português africano. No entanto os africanos, enquanto noções significativas do relato, o que revelariam à pesquisa quando dispostos como um texto corrido autônomo do principal? E o cotejo entre informações a respeito da sociedade citada, sobre o régula ou sobre o trabalho de carregador naquele contexto, o que poderiam oferecer à análise?

Das legendas que acompanham as ilustrações, algumas enfatizam o habitante da margem do rio. Por esta imagem podemos reiterar que as fronteiras ou as curvas das águas em que se deram as representações de certas África oferecem uma modalidade de produção literária que contribuiu, lembrando a expressão de Ki-Zerbo, para o processo de roedura do continente. O inventário dos exploradores mapeava a navegação e os postos de apoio nas investidas europeias, o que coloca o relato de viagem como fenômeno de dimensões culturais relevantes na vinculação com a historicidade dos importantes acontecimentos da conjuntura internacional dos anos 1870-90. É preciso também considerar a crítica, sobretudo de intelectuais africanos, da percepção da África se perder na condição de representação, de algo que não existe. ${ }^{18}$ Portanto, é crucial na análise do colonialismo e imperialismo que se deu em África, a crítica à historiografia e à antropologia. Sobremaneira, observar o quanto se dedicaram às interfaces nas quais o protagonismo africano pudesse aparecer. Talvez esta seja a terceira margem do rio e um critério para revisitar o debate constante entre as disciplinas.

Nessas curvas há um convite para compreender que ali estão habitantes dos Oitocentos, representados e representantes de algum desígnio. Seriam flagrantes de uma realidade ou apenas traços de uma memória que não cessa de ecoar no tempo, passando, inclusive, por nossas vistas neste instante?

\footnotetext{
${ }^{18}$ Mudimbe, A. 1994
} 


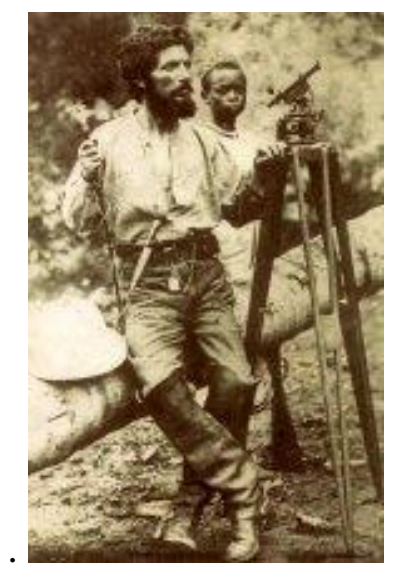

Alexandre Alberto da Rocha de Serpa Pinto. E o menino, quem seria?

Fonte principal: PINTO, Serpa. Como eu atravessei a África do Atlântico ao mar Índico, viagem de Benguella a contra-costa a-traves regioes desconhecidas; determinacoes geographicas e estudos etnographicos. Londres: Sampson Low, Marston, Searle e Rivington, 1881

\section{Bibliografia citada}

BURKE, Peter. A Escola dos Annales - a revolução francesa da historiografia. São Paulo, Editora da Unesp, 1990

CHARTIER, Roger. A história cultural: entre práticas e representações. Lisboa: Difel, 1990.

Cultura e escrita, literatura e história. Porto Alegre: Artmed Editora, 2001.

. “O mundo como representação”. Estudos avançados. São Paulo, v. 5, nº 11, 1991.

GOMES, Nilma Lino \& SCHWARCZ, Lilia K. (orgs). Antropologia e História: debate em região de fronteira. Belo Horizonte, Autêntica, 2000.

HERNANDEZ, Leila Leite. A África na sala de aula. São Paulo: Selo Negro Edições, 2005.

MARCUS, George E. Revista de Antropologia. vol.47 no.1. São Paulo, 2004. 
MUDIMBE, V. Y. The Idea of Africa. Bloomington, Idianapolis, USA: Indiana University Press and London: James Curry, 1994.

- The Invention of Africa: gnosis, philosophy and the order of knowledge. Bloomington, Indianapolis, USA: Indiana University Press and London: James Currey, 1988.

OBEYESKERE, Gananath. The Apotheosis Of Captain Cook : European Mythmaking In The Pacific, 1992.

SAHLINS, Marshall. Ilhas de história. Rio de Janeiro, Jorge Zahar Editor, 1994.

SCHWARCZ, Lilia K. M. "Questões de fronteira: sobre uma antropologia da história”. In Novos Estudos Cebrap. São Paulo, Cebrap, julho 2005, no 72, pp. 119-135. Disponível em: http://www.scielo.br/scielo.php?pid=S0101-33002005000200007\&script=sci_arttext\#nt05 (Acessado em maio de 2013).

—_ "Questão racial e etnicidade". In: Miceli (org). O que ler nas ciências sociais brasileira. São Paulo; Brasília, Ed. Sumaré, Anpocs, Capes, 1999. 